\title{
history of pcods
}
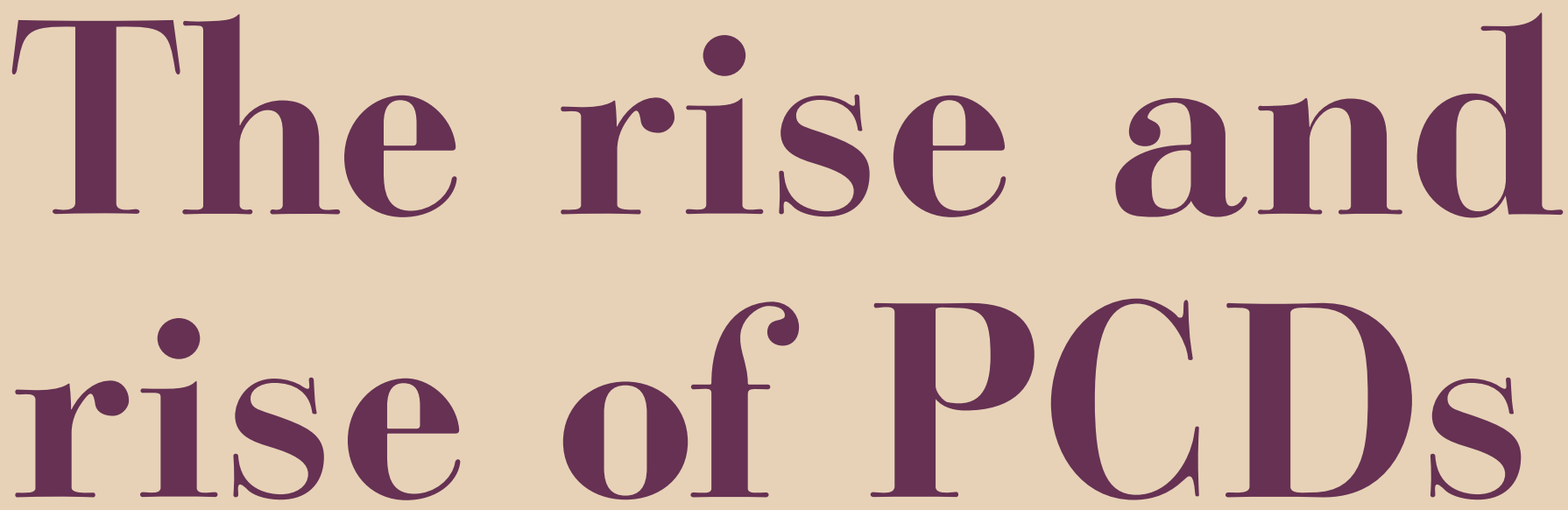

Dentistry has come a long way since its origins in the seventeenth century. One of the major changes was the introduction of the Professions Complementary to Dentistry (PCD) in the 1910s. But how did PCDs get to where they are today? By Christopher Sell.

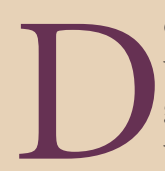

ental healthcare has taken a varied and colourful journey to get to its present state. Today, we enjoy a visit to the dentist safe in the knowledge that the dental team is overseen by professional dental authorities.

However this was not always the case. Ever since dentistry was set up as an independent medical profession in the seventeenth century, dental leaders have constantly been improving legislation and trying to prevent non-qualified practitioners from working or making unsubstantiated claims about treatment.

It was in the late 1600 s, that the term dentist - taken from the French "dentiste" - was used to describe so called "toothdrawers". In fact, in 1723 one of the first dentistry textbooks Pierre Fauchard's Le Chirurgien Dentiste (The Surgeon Dentist), was published and marked the beginning of professional dentistry.

However, while the dental profession was being established, less solicitous practices were still trading and treatment was still only an option for the wealthy. For the rest, the village blacksmith was still the answer.

The dental profession only really blossomed in the nineteenth century. In 1800 there were about 40 dentists in London and
20 in the rest of the UK. By the mid 1800s, this number had grown substantially but there were still no legal or professional controls to tackle incompetent practitioners or deal with malpractice.

Pressure to regulate the profession finally led in 1878 to the Dentists' Act followed by the Dentists' Register in 1879. The latter act meant only qualified and registered practitioners could hold the title of dentist or dental surgeon.

This shift towards greater transparency was boosted by the creation of the British Dental Association (BDA), formed in 1880 by Sir John Tomes. The BDA played a major

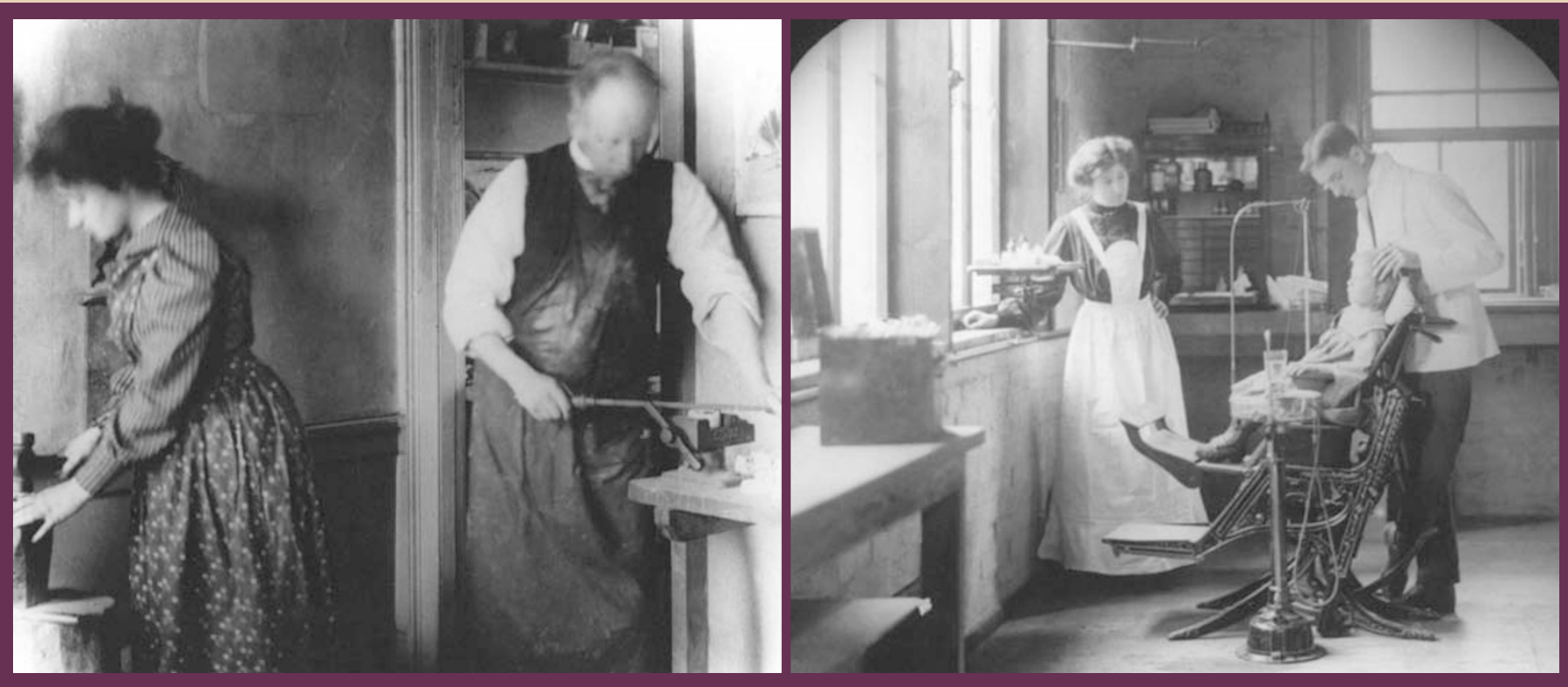

16 autumn 05

vital 
part in prosecuting illegal dentists and played a key role in reformation and development of the profession.

Despite the best efforts of the BDA and the Dentists Act, illegal practices were rife and unregistered practitioners still outnumbered qualified dentists. This situation was eventually curbed in 1921 with a revised Dentists Act, which only allowed registered dentists to practise dentistry and banned unethical advertising.

\section{PCDs arrive}

However, after the Act a new era of dentistry was quietly ushered in with the first professionals complementary to dentistry (PCD) appearing on the dental landscape.

The numbers of PCDs steadily increased over the next few years but it was during the Second World War that PCDs became properly organised.

In 1940 dentist PE Grundy from Leyland, Lancashire, launched the British Dental Nurses and Assistant Association (BDNAA) after hearing about a similar style group in the USA.

Jennifer Lavery, executive secretary of the National Examination Board of Dental Nurses said Grundy was a pioneer.

"A lot of the dentists only saw them as receptionists ... he saw much more potential in using them to directly assist him."

That organisation was followed by the British Dental Hygienists' Association (BDHA) in 1943 and the British Association of Dental Therapists (BADT) in 1960.

The early history of dental nursing was marked by the struggle members had to assert their identity in the wider profession. However this did not prevent PCD leaders from building on the pioneering work done by Grundy and others during the Second World War.

In 1943, the BDNAA set up an examination board. Only dentists were allowed to be examiners until 1978 when senior nurses were also accepted onto the board.

The association continued to adapt to its members' needs with a voluntary register in the 1960s and turned into a fully fledged union in the 1970s.

\section{PCDs today}

Lavery said that today the demand for the dental nurse examination is still very high even for non-essential qualification.

“It wasn't a mandatory qualification - it still isn't a mandatory qualification. But the numbers speak for themselves. Nurses are still putting themselves forward for qualification and it has become very acceptable to the dentist profession", she said. So acceptable in fact, that the GDC is recognising it with statutory registration.

In an effort to keep pace with a changing society, the National Examining Board for Dental Nurses widened its range of exams and introduced an NVQ certificate alongside the established National Certificate.

"It's an open access examination so it's not dependent on a training pathway though it is a traditional examination system", said Lavery.

"The reason the NVQ was introduced, which is a work-based examination system rather than one-day examination system, was because it doesn't suit everybody - while it may have been appropriate a few years ago."

However, the number of dental nurses looking for qualification is increasing. Every year 2,500 candidates are going through the national certificate system, said Lavery.

And importantly, since 1989 the board has introduced the post-certification examination, with the latest being dental radiography - a key example of how the PCD has evolved to broaden its original set of tasks and look for ways to improve its members in the field.

"It is where dental nursing is going, dental nurses do a lot more than they did in the past and I can see with statutory registration the potential to do very much more in the future", said Lavery.

Registration is having an impact on other PCDs as well. Margaret Ross, President of the BDHA believes it will allow hygienists to expand their role in the surgery and take on greater responsibility.

"We will be able to undertake more work. The Section 60 order is going to open up all sorts of avenues”, Ross said. “Two new groups of people will commence training as a result A school for hygienists, Rochester USA c1926.

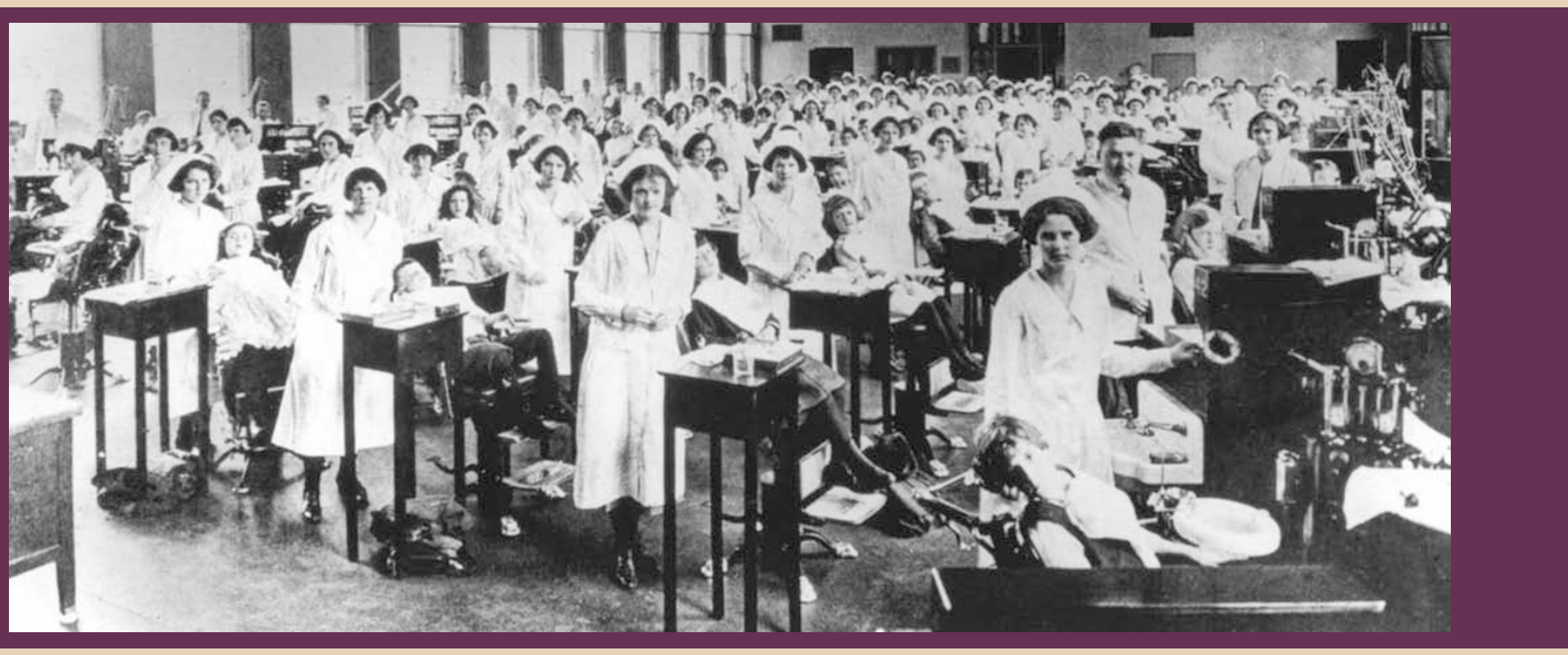


of this new order. They are orthodontic therapists and clinical dental technicians who will be able to construct and fit dentures which is something they haven't been able to do in the past."

This wider role is somewhat removed from its origins in the UK. The hygienist's role, which first appeared in the USA in 1914 and in 1916 in the UK, was developed from so called 'dental dressers' who worked for local education authorities to educate schoolchildren.

UK hygienists' role was trimmed by the 1921 Dentist Act, which restricted "the performance of minor dental work under personal supervision of a registered dentist, by a person who is not a dentist".

It was not until the RAF began to train dental hygienists in 1943 , to maintain the dental health of air crews, that the post became better known. This in fact resulted in the 1956 Dentists Act, which established training courses for dental hygienists in various dental hospitals such as in Manchester in 1959 and in Birmingham in 1961.

As Ross explained, the role of the PCD is gaining momentum. The role of the hygienist today, administering blocks and working without a dentist, is far removed from the original concept of a hygienist 50 years ago. "I am extremely confident that the role of the hygienist will continue and it will only ever become more significant and I think that the contribution to dentistry that all PCDs can make will only ever grow."
Professor Emeritus of Dental Public Health at London University Stanley Gelbier said that with the formal recognition of PCDs by the GDC, these dental practitioners will go from strength to strength.

"At present, PCDs can only work to a written prescription from a dentist. It will be interesting to see if some government in the future suggests that hygienists should be capable of carrying out prevention without a dentist's influence and set up stand-alone practices", he said.

\section{${ }^{66}$...I think that} the contribution to dentistry that all PCDs can

\section{make will only \\ ever grow.}

Professor Gelbier, who is also a dental historian, also alluded to the changes being made for therapists, who previously could only work in the CDS or HDS but now, can work with dentists in general practice. As a result they will become more popular and hopefully make a major contribution to the care of patients.
This represents a real advance for dental therapists, who, having been introduced in 1960 against the wishes of the profession have become, according to Gelbier, highly valued members of the dental team.

Initially the dental auxillaries (as they were known) were confined to the school dental services - the forerunner to the community dental service. Between 1960 and 1983, 60 women a year were trained at New Cross Hospital in south London, thus not associated with any dental school. Nowadays they are trained in numerous dental schools along with dental undergraduates as well as independent PCD schools in Portsmouth and Salford.

And this surely is the key to PCD development. From their early days as a fledgling professional body, trying to establish its own identity, they have struggled to improve and build upon what they can offer, and over time, they have been allowed to implement changes that were seen as necessary. The dental world is surely a better place for it.

Ross concludes, "I think dental nurses will move along, maybe in the medical model of things, where you have nurse practitioners, nurse consultants, nurse specialists and all that".

"I think dentistry lacked vision in the past ... but I think that that is certainly the way things will undoubtedly progress in the future. However, with each member of the team still having their own specific role to play in patient care." Army Medical Services Museum.

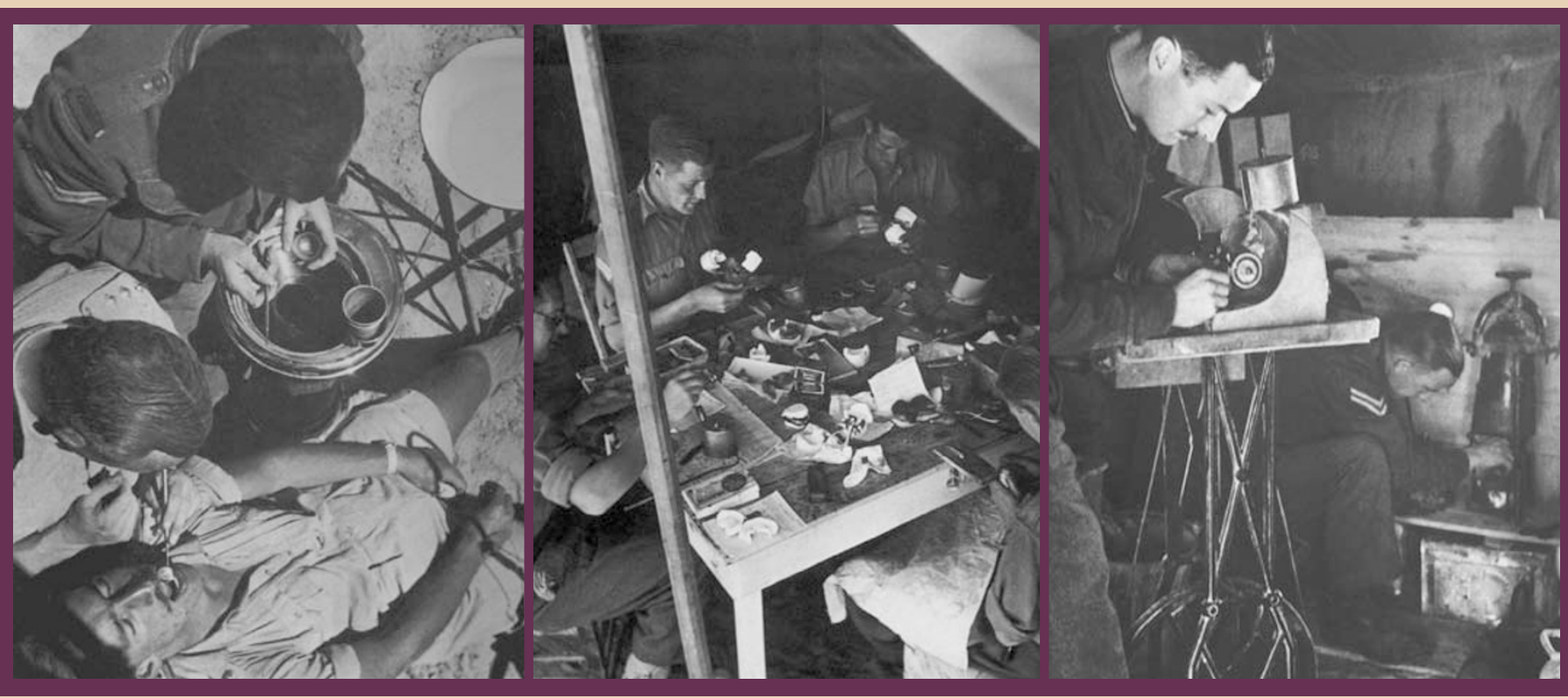

